\title{
ВЛИЯНИЕ ИНСТИТУТОВ АСИММЕТРИЧНОГО ФЕДЕРАЛИЗМА НА СТАБИЛИЗАЦИЮ ФЕДЕРАЛЬНОЙ И РЕГИОНАЛЬНОЙ ПОЛИТИКИ
}

\begin{abstract}
Аннотация: Данная статья представляет собой теоретический обзор понятия асимметричного федерализма в многонациональных государствах. Асимметрия показана как инструмент сохранения федераиии, хотя является нестабильным институтом с точки зрения того, что она в той или иной степени затрагивает всех участников политического действа. В данной связи предметом исследования является процесс противостояния между центром и национальными меньшинствами, очевидно угрожающего существующей политической системе, решение центра о предоставлении асимметричным образованиям автономии может обеспечить взаимовыгодное сотрудничество. Автор в качестве аргументации использует теоретико-игровую базу, связывая стратегические иели федеральной и региональных элит с вопросами общегосударственной стабильности. Ввиду особо важности вопроса создания и закрепления асимметричных институтов в статье также используется институциональный подход. Научная новизна данного исследования состоит в том, что асиммет-ричный федерализм может быть представлен как «вложенная (гнездовая) игра», где события, происходящие в рамках этноначионального сегмента, определяют ситуацию в маситабах всей федерации. Предполагается, что правила асимметричного федерализма прежде всего являются нестабильныли с точки зрения того, что они влияют на всех участников политического процесса в государстве. Данный подход иллюстрирует анализ развития российского федерализма. Автор статьи иллюстрирует теоретические идеи на примере анализа российских федеральных институтов, созданных в 1990-х годах в ходе переговоров между центром и сепаратистски настроенными элитами региональных меньшинств.
\end{abstract}

Abstract: This article represents a theoretical overview of the concept of asymmetrical federalism in multinational states. Asymmetry is shown as a tool of federation conservation, although it is an unstable institution in that it affects all the participants of political actions to some extent. In this regard the subject of research is the process of confrontation between the center and the national minorities, obviously threatening the existing political system; the decision of the center on providing the asymmetric entities with autonomy can lead to mutually beneficial cooperation. The author uses the argument as a game-theoretic framework, linking the strategic goals of the federal and regional elites with the issues of nationwide stability. Particularly in view of the importance of the creation and consolidation of asymmetric institutions, the institutional approach is also used in this article. The scientific novelty of this study is that asymmetric federalism can be represented as a "nested (nesting) game", where the events, occurring within the ethno-national segment, determine the situation across the whole federation. It is assumed that the rules of asymmetrical federalism are primarily not stable, in view of the fact that they affect all the participants of the political process in the State. This approach illustrates the analysis of the development of Russian federalism. The author of the article illustrates the theoretical ideas on the example of analysis of the Russian federal institutions established in the 1990s during the negotiations between the center and regional separatist minority elites.

Ключевые слова: асимметричный федерализм, институты, стабильность федерации, многонациональное государство, российский федерализм, «вложенная (гнездовая) игра», этнонационализм, регионы, сепаратизм, наииональные меньшинства

Keywords: asymmetric federalism, institutions, federation stability, multinational state, Russian federalism, "nested (nesting) game", ethno-nationalism, regions, separatism and national minorities.

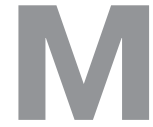

ногонациональные государства являются результатом объединения разных народов с традиционными местами проживания в единое государство. Как следствие, они сталкиваются с проблемой адаптации национальных меньшинств, определяемых как культурные группы, претендую- щие на самоопределение по территориальному признаку ${ }^{1}$. Многонациональные федеративные системы

\footnotetext{
${ }^{1}$ Keating M. So many nations, so few states: Territory and nationalism in the global era. In A. G. Gagnon \& J. Tully (Eds.), Multinational democracies. Cambridge, UK: Cambridge University Press. 2001.- pp. 43-62.
} 
решают эти проблемы посредством институтов асимметричной автономии ${ }^{2}$. Национальным меньшинствам предоставляется особая (т.е. асимметричная) автономия для развития на субрегиональном уровне - преимущество, которым пользуется доминирующая группа в масштабах государства для самоопределения как правящее большинство ${ }^{3}$.

Определенная степень асимметрии свойственна всем, а не только многонациональным федеративным политическим системам. Регионы отличаются по размерам, демографическим характеристикам, климатическим условиям. Эти объективные географические, культурные, социально-экономические факторы, как правило, и определяют де-факто политическую асимметрию. Их необходимо дифференцировать от де-юре или конституционной асимметрии, когда конституция по-разному трактует субъекты федерации, предоставляя одним субъектам больше самостоятельности, чем другим ${ }^{4}$. Это можно наблюдать не только в полноправных федерациях наподобие Канады, Бельгии, Индии и России, но и в конституционно закрепленных децентрализованных союзах, таких как Южная Африка и Великобритания.

Несмотря на то, что вопросы, касающиеся асимметрии, имеют огромную практическую значимость, так как они пытаются решить конкретные проблемы, возникающие вследствие политического раскола в многонациональном государстве и угрожающие сепаратистскими конфликтами, академическое понимание динамики их развития и механизмов их функционирования все еще недостаточно исчерпывающее 5 . В частности, исходя из нормативных оснований, ученые, изучающие многонациональные государства, согласились с необходимостью создания асимметрии с целью урегулировать политические требования права на самоопределение по территориальному признаку ${ }^{6}$.

\footnotetext{
${ }^{2}$ Stepan A. Arguing comparative politics. Oxford, UK: Oxford University Press. 2001. 26(2). - pp. 327-328.

${ }^{3}$ Kymlicka $W$. Is federalism a viable alternative to secession? In P. Lehning (Ed.), Theories of secession (p. 133). London: Routledge. 1998.

${ }^{4}$ Burgess M., \& Gress F. Symmetry and asymmetry revisited. In R. Agranoff (Ed.), Accommodating diversity: Asymmetry in federal states (p. 53). Baden-Baden, Germany: Nomos. 1999.

${ }^{5}$ Congleton R.D., Kyriacou A., \& Bacaria, J. A theory of menu federalism: Decentralization by political agreement. Constitutional Political Economy, 2003. 14, 170.

${ }^{6}$ Agranoff $R$. Intergovernmental relations and the management of asymmetry in federal Spain. In R. Agranoff (Ed.), Accommodating diversity: Asymmetry in federal states (p. 97). Baden-Baden, Germany:
} Nomos.1999.
Возможность асимметричных систем оставаться стабильными, однако, является вопросом дискуссионным.

Асимметрия может быть определена как особенность многонациональных федеральных систем, благодаря которой национальные образования (так называемые национальные меньшинства) могут де-юре пользоваться большими правами, чем на основе разделения по региональному принципу (так называемое национальное большинство), тем самым предопределяя дифференцированное отношение со стороны центра7. Это свидетельствует о том, что стабильность асимметричных федеративных политических систем зависит от взаимодействия целого сложного комплекса акторов, определяемых как большинством-меньшинством, так и принципом разделения центра и регионов.

Модели функционирования асимметричного федерализма в многонациональных государствах можно представить в виде игры. Так, учитывая ситуацию, когда национальное меньшинство противостоит центру и реально угрожает расколом, готовность центра предоставить асимметричную автономию региональному меньшинству решает так называемую дилемму заключенного ${ }^{8}$ и обеспечивает взаимовыгодное сотрудничество. Тем не менее, расширяя полномочия асимметричной автономии для миноритарных регионов, федеративная асимметрия создает третьего игрока - депрессивные регионы. Исходя их этого, можно рассматривать асимметричный федерализм как «вложенную игру»", где события на этнонациональной арене (структурированной по принципу разделения на большинство и меньшинство) определяют ситуацию в масштабах всей федерации. Ввиду того, что асимметричный федерализм вбирает в себя всех участников политического действа, он является нестабильным институтом. Это можно проследить на примере ряда стран, в том числе России и российских федеральных

\footnotetext{
${ }^{7}$ Kymlicka $W$. Is federalism a viable alternative to secession? In P. Lehning (Ed.), Theories of secession (p. 133). London: Routledge. 1998.

${ }^{8}$ Дилемма заключенного (модель игры, показывающая, как рациональное поведение на микроуровне приводит к нерациональному результату на макроуровне; каждому игроку приходится делать выбор между сотрудничеством и соперничеством с другим игроком, при условии, что каждый не знает о решении другого; максимальный общий выигрыш получается при сотрудничестве обоих игроков, однако если один решит сотрудничать, а другой соперничать, то для первого это создаст результат худший, чем если бы соперничали оба; в результате рациональным выбором каждого из них становится соперничество, хотя общая выгода обоих была бы выше, если бы и тот, и другой выбрал сотрудничество)

${ }^{9}$ Tsebelis G. Nested games: Rational choice in comparative politics.
} Berkeley: University of California Press. 1990. 
DOI: 10.7256/1811-9018.2014.1.10711

При цитировании этой статьи сноска на доі обязательна

\section{Право и политика 1 (169) 2014}

институтов, созданных в 1990-х годах в ходе переговоров между центром и сепаратистски настроенными элитами региональных меньшинств - то, что Р. Уоттс назвал «наиболее сложным современным примером конституционной асимметрии» ${ }^{10}$.

В рамках подхода к теории игр «самодостаточными институтами являются такие институты, в которых поведение каждого игрока является лучшим ответом» и «ни у кого нет причины отклоняться от поведения, предписанного этими институтами» ${ }^{11}$. Данная концепция теории федерализма в части, касающейся стабильности федерации, нередко применяется к самодостаточным институтам в том смысле, что принципы федерализма должны быть универсальными для должностных лиц на всех уровнях управления ${ }^{12}$. Теория асимметричного федерализма, представленная здесь, подытоживает данные подходы и связывает асимметрию и стабильность на уровне выбора центральных и региональных акторов для получения очевидных аргументов в пользу того, что асимметричные меры ограничивают отклонение от принятых норм и задают рамки законопослушного поведения, или же наоборот.

Прямой угрозой стабильности в любой федеративной системе является выход из состава федерации ${ }^{13}$. Некоторые акторы могут не только не исполнять отдельные общие правила, но и отказаться от выполнения всех предписаний федеративного образования. В многонациональных государствах, где национальные меньшинства стремятся к самоопределению, эта проблема усугубляется тем, что наиболее очевидной задачей для достижения этой цели является создание другого суверенного национального государства ${ }^{14}$. Неудивительно, что стабильность многонациональных федеративных систем систематически подвергается опасности по причине самой своей природы, где центру приходится сталкиваться с претензиями периферийных наций на суверенитет в рамках существующего государства. При этом национальное

\footnotetext{
${ }^{10}$ Watts R.L. Comparing federal systems (2nd ed.). Montreal: McGillQueen's University Press. 1999. - P. 67.

${ }^{11}$ Greif A., \& Laitin D.D. A theory of endogenous institutional change. American Political Science Review, 2004. 98, 633.

${ }^{12}$ De Figueiredo R.J.P., McFaul M., \& Weingast B.R. Constructing selfenforcing federalism in the early United States and modern Russia. Publius, 2007. 37(2), 160-189.

${ }^{13}$ Filippov M., Ordeshook P.C., \& Shvetsova O. Designing federalism: A theory of self-sustainable federal institutions. Cambridge, UK: Cambridge University Press. 2004. P. 13.

${ }^{14}$ Hechter $M$. Containing nationalism. Oxford, UK: Oxford University Press. 2000. - P.116.
}

меньшинство ставит под сомнение правомочность многонационального государственного образования и стремится к размежеванию. В то же время данную теорию нельзя применить ко всем без исключения многонациональным системам, все зависит от внешних условий, определяющих требования сепаратизма национальных меньшинств. Возможно, важнейшим из таких условий был бы переход к демократии ${ }^{15}$. Однако и в устоявшихся демократиях, таких как Испания или Канада, наблюдаются сепаратистские настроения.

Именно готовность меньшинства к отделению, с которым сталкивается центр с предложением асимметричной автономии, объясняет переход от симметричного институционального к асимметричному федерализму. Это есть теоретическое объяснение того, почему асимметрии де-юре имеют жизненно важное значение для многонациональных государств-мнение, которое в научной литературе до сих пор защищают по нормативным основаниям ${ }^{16}$.

Однако проблемы институциональной стабильности в многонациональных государствах не регулируются лишь при успешном решении вопросов асимметрии в ходе договоренностей между политическими элитами национальных большинства и меньшинства. Игра на противостояние не происходит в «вакууме»- она встроена в «более высокий сетевой порядок» ${ }^{17}$ федеральной игры. Успешные стабилизирующие отношения между большинством и сторонниками отделения должны рассматриваться в перспективе общего развития федеративной системы, где в отсутствие третьей стороны результаты любой договоренности должны быть самодостаточными и где переговоры центра с официальными представителями субнациональных блоков происходят не изолированно, а влияют на выбор стратегии другими региональными образованиями ${ }^{18}$. Асимметрия устанавливает взаимосвязь между этими двумя факторами ввиду того, что асимметричные федеральные институты не являются полностью самостоятельными.

С.Д. Тарлтон в своих ранних работах по асимметричному федерализму рассматривал проблемы асимметрии в свете стабилизации федеративных систем:

\footnotetext{
${ }^{15}$ Hechter $M$. Containing nationalism. Oxford, UK: Oxford University Press. 2000. - P.93.

${ }^{16}$ Requejo F. Federalism and national groups. International Social Science Journal, 2001.53 (167). - P. 45.

${ }^{17}$ Tsebelis $G$. Nested games: Rational choice in comparative politics. Berkeley: University of California Press. 1990. - P. 245.

${ }^{18}$ Solnick $S$. Will Russia survive? Center and periphery in the Russian Federation. In B.R. Rubin \& J. Snyder (Eds.), Post-Soviet political order: Conflict and state building (P. 59). London: Routledge. 1998.
} 
«Следует подчеркнуть в данной связи, что там, где случаются конфликты внутри федерации, это, скорее всего, связано с недовольством лишь одного или нескольких федеративных образований. Редкий конфликт происходит между центральным правительством и всеми составными частями федерации одновременно. Поэтому конфликт внутри федерации вероятнее всего возникнет там, где отношения между местными и центральными властями развиваются по асимметричному сценарию и где асимметрия характерна лишь для нескольких составных частей государства. Если говорить о реальных масштабах, то степень равновесия или конфликта внутри федеративной системы можно рассматривать как функцию симметричной или асимметричной модели, преобладающей в системе» ${ }^{19}$.

Теория игр соотносится с оригинальным понятием Тарлтона -«теоретическими спекуляциями» ${ }^{20}$. При асимметричном федерализме в многонациональном государстве федеральная игра распространяется на три типа игроков: представители исполнительной власти частей федерации, имеющие особый статус, представители исполнительной власти частей федерации со средним статусом и должностные лица на уровне федерального правительства. Данные типы игроков могут быть дифференцированы по их целям в отношении системы в целом: «Должностные лица с особым статусом заинтересованы в сохранении асимметричной системы, так как только асимметрия дает возможность национальным меньшинствам равные с точки зрения национального самоопределения права» ${ }^{21}$.

Хотя центр может вступить в конфронтацию с различными типами составных частей и де-юре симметричными федеративными системами (например, экономически более сильными в отличие от слабых регионов), асимметрия де-юре институционализирует различия между игроками на уровне правил федеральной игры. Как следствие - центр сталкивается в процессе переговоров с целыми коалициями, для которых может быть характерна определенная институционализация интересов, более стабильных, чем формальные договоренности между равными по статусу единицами в более симметричных образованиях.

Учитывая реальность угрозы несоблюдения регионами федеральных законов (почти на официальном

${ }^{19}$ Tarlton C.D. Symmetry and asymmetry as elements of federalism: A theoretical speculation. Journal of Politics, 1965. 27(4), 871.

${ }^{20}$ Ibid.

${ }^{21}$ McGarry J. Federal political systems and national minorities. In A. L. Griffiths (Ed.), Handbook of federal countries 2002 (P. 434). Montreal: McGill-Queen's University Press. уровне) и итоги периферизации федераций, можно предположить, что у федеральных чиновников может возникнуть желание полностью трансформировать существующую систему асимметричного федерализма, опирающуюся на этнонациональную основу, хотя именно она служит гарантом обеспечения их интересов. В этой связи С. Солник описывает стратегию центра как «разделяй и властвуй», когда центр стремиться заключать взаимовыгодные соглашения с отдельными, наиболее сильными на общем фоне регионами, что наглядно иллюстрирует характерные особенности асимметричного федерализма 22 . При этом должностные лица в правительственном центре оценивают результаты подобного взаимного сотрудничества выше, чем при сохранении статуса-кво, и могут быть заинтересованы в использовании своего доминирующего положение в общей институциональной иерархии для лоббирования идей автономии, способных сделать такое сотрудничество весьма продуктивным.

Как представляется, асимметричный федерализм, особенно в многонациональных государствах, создавая оптимальные стратегии политической игры и особые типа игроков, таким образом, в институциональном отношении облегчает сотрудничество по линии центр-регионы, направленное как на поддержание ассиметричного порядка (регионы с особым статусом и центр), так и на его нивелирование («правильные» регионы и центр).

Говоря об угрозе стабильности, отметим, что центральная власть всегда в той или иной степени стремится подорвать основы системы асимметричного федерализма, поскольку институциональные различия затрудняют координацию ее элементов, и добиться жесткого подчинения центру - важнейшего условия «самодостаточности федерализма», согласно Де Фигейредо и Уэйнгасту ${ }^{23}$. В противоположность традиционному подходу, при асимметричном федерализме центральное правительство может выбирать между партнерством в рамках коалиции и максимизацией собственной власти.

В пользу целесообразности асимметричного федерализма можно привести тот довод, что наличие признанной асимметрии снижает мотивацию для меньшинств нарушать официально установленные рамки институционального взаимодействия. С другой

${ }^{22}$ Solnick $S$. Will Russia survive? Center and periphery in the Russian Federation. In B. R. Rubin \& J. Snyder (Eds.), Post-Soviet political order: Conflict and state building (P. 62). London: Routledge. 1998.

${ }^{23}$ De Figueiredo R.J.P., \& Weingast B.R. Self-enforcing federalism. Journal of Law, Economics, and Organization, 2005. 21(1), 127. 
DOI: 10.7256/1811-9018.2014.1.10711

При цитировании этой статьи сноска на доі обязательна

\section{Право и политика 1 (169) • 2014}

стороны, упомянутая выше «вложенная игра» подразумевает, что асимметричные институты не самодостаточны, когда речь идет о мотивациях акторов и на этнонациональном уровне, и на уровне федерации. Без предварительной договоренности по вопросам асимметричного распределения власти действуют усредненные равновесные модели федерализма при наличии лишь двух типов игроков. Логика мультинациональной игры применяется всякий раз, когда мобилизованные национальные меньшинства бросают вызов центральной власти (т.е. выступают на поле этнонационализма) в существующей федеральной системе или когда урегулирование этнического конфликта приводит к формированию асимметричных федеративных систем в ранее унитарном государстве. Отсюда следует вывод о том, что проблемы институциональной стабильности являются неотъемлемым атрибутом многонациональных федеративных систем.

Если рассматривать в данном теоретико-практическом разрезе опыт Российской Федерации, здесь очевидно то преимущество, что изложенную теорию иллюстрирует множество ее ответвлений и разновидностей в рамках одного государства, особенно учитывая тот факт, что в 1990-х годах политическая власть в России была разделена, а затем передел власти происходил регулярно на фоне усиления асимметрии в вопросах региональной автономии. Этот процесс можно разбить на три этапа. Первый этап начинается с проблем сепаратизма, возникших на этнонациональной почве в ходе распада Советского Союза, и заканчивается принятием принципов асимметрии, предусмотренных положениями Федеративного договора 1992 года. Второй этап можно выделить, исходя из поведения трех игроков так называемой «вложенной игры» во время переговоров о принятии Конституции летом 1993 года. Третий этап затрагивает серию двусторонних договоров по вопросам асимметрии, подписанных центром и отдельными регионами в период между 1994 и 1998 годами в результате длительной конфронтации и «обновленной» игры.

После глобальных национальных трансформаций и изменения государственных границ, имевших место во время и после распада Советского Союза, элиты национальных меньшинств получили возможность открыто бросить вызов прежнему государственному порядку и установить новые рамки федерации. Политические лидеры 25 регионов наряду с бывшими советскими социалистическими республиками и автономными областями объявили о своем суверенитете в 1990-м и 1991-м годах ${ }^{24}$. Это и стало началом игры на противостояние в этнонациональной борьбе.

Из всех деклараций о суверенитете намерения республик Татарстан и Чечено-Ингушетии стать независимости имели самые далеко идущие последствия. В то время как другие регионы определяли свой суверенитет в рамках Российской Федерации, эти две республики выразили желание стать независимыми государствами $^{25}$. Официальным Указом Чечено-Ингушетии республика была провозглашена «суверенным государством, созданным в результате самоопределения чеченского и ингушского народов» ${ }^{26}$. Декларация Татарстана была более либеральной в отношении других национальностей, но не менее амбициозной, и здесь речь шла о государственном суверенитете ни относительно России или Советского Союза, а в качестве «реализации неотъемлемого права татарской нации, всего народа республики на самоопределение» ${ }^{27}$.

Вновь созданные элиты Татарстана и Чечни как игроки, способные стать серьезной проблемой для территориальной целостности новой Федерации, открыто заявили, что стремятся к созданию собственных суверенных государств. Другие декларации суверенитета были менее радикальными и были направлены главным образом на поддержание статуса республик в рамках единого государства с добровольным признанием себя в качестве равноправных участников Федеративного Договора ${ }^{28}$. И тем не менее, это были декларации о суверенитете, то есть акты неповиновения, заявленные территориями иногда гораздо большими по размеру, чем бывшие советские республики, и, по сути, претендующие на права суверенных независимых государств, причем в то время, когда этнополитические конфликты захлестнули всю Восточную Европу ${ }^{29}$.

Установление общепризнанных рамочных правил было жизненно важной задачей для сдерживания

\footnotetext{
${ }^{24}$ Treisman D.S. Russia's «ethnic revival": The separatist activism of regional leaders in a postcommunist order. World Politics, 1997. 49, 226-228.

${ }^{25}$ Heinemann-Gruder A. Der heterogene Staat. Foderalismus und regionale Vielfalt in Rufiland [The heterogeneous state. Federalism and regional diversity in Russia]. Berlin: Arno Spitz. 2000. - P. 131.

${ }^{26}$ Tishkov V. Ethnicity, nationalism and conflict in and after the Soviet Union: The mind aflame. Thousand Oaks, CA: SAGE. 1997. - P. 56.

${ }^{27}$ Ibid.

${ }^{28}$ Heinemann-Gruder A. Der heterogene Staat. Foderalismus und regionale Vielfalt in Rufiland [The heterogeneous state. Federalism and regional diversity in Russia]. Berlin: Arno Spitz. 2000. - P. 131.

${ }^{29}$ Gorenburg D. Minority ethnic mobilisation in the Russian Federation. Cambridge, UK: Cambridge University Press. 2003. - P. 126.
} 
центробежной динамики - закономерного следствия националистических настроений и требований суверенитета. В этих условиях ключевые политические акторы страны сочли целесообразным подвести под фактическую асимметрию некую правовую базу в форме Федерального Договора от 31 марта 1992 года, ставшей приложением к Конституции России 1978 года ${ }^{30}$. Согласно Федеральному Договору, полномочия различных частей федерации неравномерно распределялись по трем категориям:

1. Национально-государственные республики.

2. Национально-территориальные образования.

3. Административно-территориальные образования.

Каждая из этих групп подписала отдельный субдоговор с центром, и все три текста в совокупности составили Федеративный Договор 1992 года $^{31}$. Существование трех различных договоров усугубили различия между асимметричными частями федерации ${ }^{32}$. Таким образом, Российская Федерация изначально создавалась как асимметричная политическая система с 21 республиками, 11 автономными областями и 57 российскими регионами, что позволило не только сохранить, но в дальнейшем и расширить толкование советского этнотерриториального принципа федерализма, который традиционно делил государство на национальные образования (так называемые национальные меньшинства) и региональные единицы (так называемое национальное большинство).

Как отмечали западные наблюдатели, принципы асимметрии удовлетворяли чаяния большинства регионов, объявивших о своем суверенитете ${ }^{33}$. Совместно подписанный центром и регионами, этот договор создал основу для разработки первого набора правил асимметричного федерализма для нового российского государства. Они оказались приемлемыми для большинства сепаратистски настроенных

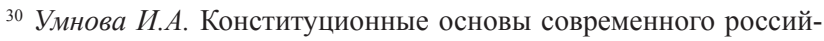
ского федерализма. - М.: ДЕЛО, 1998. - С. 53.

31 Федеративный договор (Договор о разграничении предметов ведения и полномочий между федеральными органами государственной власти Российской Федерации и органами власти суверенных республик в составе Российской Федерации). (Москва, 31 марта 1992 г. / http://constitution.garant.ru/act/federative/170280/

${ }_{32}$ Медведев Н.П. Роль декларации о государственном суверенитете РСФСР и федеративного договора в процессе трансформации территориально-политического устройства современной России./ Под ред. Р.Г. Абдулатипова (Вопросы национальных и федеративных отношений). - М.: РАГС, 2003. - С. 23.

${ }^{33}$ Heinemann-Gruder A. Der heterogene Staat. Foderalismus und regionale Vielfalt in Rufiland [The heterogeneous state. Federalism and regional diversity in Russia]. Berlin: Arno Spitz. 2000. - P. 153. национальных меньшинств, стремящихся к независимости в период после распада СССР. Республики, которые открыто объявили о своем суверенитете в 1991-м году, теперь были готовы подписать то, что нельзя было назвать международным договором между независимыми государствами, но вполне можно было отнести к соглашениям между федеральным центром и частями федерации. Тем не менее, единодушия по вопросам асимметричного федерализма не наблюдалось, поскольку продолжалось противостояние центра и двух республик, Татарстана и Чечни, по-прежнему стремящихся к независимости. Как оказалось, асимметрия, заложенная Федеративным Договором, была недостаточно действенным инструментом, чтобы обеспечить сотрудничество и предложить реальную альтернативу отчуждению от федерации региональных элит Чечни и Татарстана.

Разработка и принятие Конституции 1993 года стали следующим шагом к созданию современного российского федерализма. Асимметричные различия между национальными меньшинствами и региональным большинством были закреплены в Федеративном Договоре в результате противостояния регионов на этнонациональной почве, что обусловило расклад сил на переговорах в конституционном собрании, созванном Ельциным в июле 1993 года. Представители национальных республик тогда выразили опасения в отношении доминирования русского большинства, стремясь к созданию конфедерации «свободных наций». Представители России были против такого подхода. Они опасались маргинализации русского большинства в ситуации, когда было неясно, каким образом российский народ может быть представлен в конфедерации, состоящий из различных народностей. Основным камнем преткновения на этом форуме был конфликт между республиками и российскими регионами «большинства», которые выступали против идеи о структурном характере формирующейся федеративной системы. В то время как группа республик настаивала на равенстве суверенных государств, российские регионы выдвинули принцип равенства частей федерации в качестве их условия утверждения проекта конституции. Это подтверждает описанное выше предположение о противоположных целях национальных меньшинств и регионального большинства в многонациональных государствах.

Центр играл на обеих сторонах и в целом обернул ситуацию в свою пользу. Проект Конституции предоставил президенту право принимать меры по защите суверенитета Российской Федерации, назначать судей 
DOI: 10.7256/1811-9018.2014.1.10711

При цитировании этой статьи сноска на доі обязательна

\section{Право и политика 1 (169) 2014}

Конституционного суда, проводить референдумы, объявлять региональное законодательство недействительным с точки зрения Конституции, вводить чрезвычайное положение с предоставлением ему в связи с этим особых полномочий и налагать вето на законопроекты, которые могли быть приняты только большинством голосов из двух третей в обеих палатах.

В конечном итоге трудности переговоров по вопросам Конституции, целью которых было установление правил для многонационального государства в условиях различия целей асимметрично институцианализированных участников, стали очевидными, когда конституционное собрание не смогло достичь консенсуса. Однако, несмотря на недовольство республик, Российская конституция де-юре сохранила принципы асимметрии и разделение регионов на три категории, предусмотренные Федеральным Договором ${ }^{34}$.

Основы конституционной асимметрии стали детально прорабатываться и дополняться, начиная с 1994 г., когда центр вступил в процесс переговоров по подписанию двусторонних договоров с отдельными регионами по разграничению юрисдикций, изложенных в Конституции 1993 года, с целью уточнить и при необходимости модифицировать их в соответствии с принципами асимметрии. В некоторых из этих договоров юрисдикции асимметрично «сдвинуты» между уровнями власти, например, от федерального уровня к уровню региональной компетенции. Двусторонние условия договора расширяли юрисдикции для некоторых регионов - одна из характерных процедур для закрепления асимметричного федерализма ${ }^{35}$. Хотя первая волна договоров была подписана с национальными меньшинствами, позже обновленные двусторонние договоренности с некоторыми регионами стали противоречить национальному подходу к отдельным сообществам и особому статусу федеративных единиц в связи с их асимметричным положением, закрепленным Федеральным Договором и подтвержденным Конституцией. В период между заключением первого Договора с Республикой Татарстан в феврале 1994 года и последнего - с городом федерального значения Москвой в июне 1998 года - между региональными и центральными

\footnotetext{
${ }^{34}$ Obydenkova A. Institutional tools of conflict management - asymmetrical federalism in ethnic-territorial conflicts: Quantitative analysis of Russian regions. Peace, Conflict and Development, 2005. 7, 266.

${ }^{35}$ Watts R.L. The theoretical and practical implications of asymmetrical federalism. In R. Agranoff (Ed.), Accommodating diversity: Asymmetry in federal states (pp. 24-42). Baden-Baden, Germany: Nomos. 1999. - P. 37.
}

органами государственной власти было заключено 46 двусторонних договоров.

Отметим, что заключаемые начиная с лета 1997 года договора можно отнести к формальным попыткам центра уменьшить полномочия «асимметричных» регионов. Значимость более ранних договоренностей отошла на второй план, поскольку большинству регионов были предложены стандартизированные договора. Целью этих мер было выравнивание регионов и модернизация федеративной системы и ее институтов в сторону меньшей асимметричности ${ }^{36}$. Конечно, такие попытки вызывали у некоторых республик опасения по поводу потери важных полномочий. Уже в 1995 году Татарстан, Башкортостан и Саха подписали совместное заявление с требованием того, чтобы любые переговоры по новым договорам учитывали существенные различия между тремя типами федеральных единиц, то есть республик, автономных областей и административно-территориальных образований. При этом двусторонние договора оставались в силе и подтверждали особый статус нацменьшинств. Но это было лишь начало отхода от прежних договоренностей.

Анализ показывает, как с помощью игрового институционального подхода можно объяснить некогерентный, на первый взгляд, процесс федерализации в России. Хотя сепаратизм может быть смягчен благодаря ряду «асимметричных» договоренностей, эта система в определенном смысле является заложницей непрерывного торга ее участников за роль и место в федерации. Разногласия по поводу сути федерализма - фундаментального вопроса для России - являются центральной точкой отсчета при «вложенной многонациональной игре», свойственной всем асимметричным федеративным системам и, тем не менее, способствующей поиску оптимальных политических решений в интересах федерации в целом.

Что касается теоретических споров о стабильности федерации в асимметричных системах, то, как отмечалось выше, представляется важным отделить функцию асимметрии как обязательного договора, способствующего усилению стабильности, от функции асимметрии как структурного принципа федеративной системы в целом (не самодостаточной, а следовательно, едва ли стабильной). С этой точки зрения аргументы в пользу и против стабилизирующей роли института асимметричного федерализма не являются взаимоисключающими, хотя по отдельности могут быть вполне обоснованными.

\footnotetext{
${ }^{36}$ Filippov M., Ordeshook P.C., \& Shvetsova O. Designing federalism: A theory of self-sustainable federal institutions. Cambridge, UK: Cambridge University Press. 2004. - P. 136.
} 


\section{Библиография:}

1. Медведев Н.П. Роль декларации о государственном суверенитете РСФСР и федеративного договора в процессе трансформации территориально-политического устройства современной России./ Под ред. Р.Г. Абдулатипова (Вопросы национальных и федеративных отношений). - М.: РАГС, 2003. - С. 23.

2. Умнова И.А. Конституционные основы современного российского федерализма. - М.: ДЕЛО, 1998. - C. 53.

3. Agranoff R. Intergovernmental relations and the management of asymmetry in federal Spain. In R. Agranoff (Ed.), Accommodating diversity: Asymmetry in federal states (p. 97). Baden-Baden, Germany: Nomos.1999.

4. Burgess M., \& Gress F. Symmetry and asymmetry revisited. In R. Agranoff(Ed.), Accommodating diversity: Asymmetry in federal states (p. 53). Baden-Baden, Germany: Nomos. 1999.

5. Congleton R.D., Kyriacou A., \& Bacaria, J. A theory of menu federalism: Decentralization by political agreement. Constitutional Political Economy, 2003. 14, 170.

6. De Figueiredo R.J.P., \& Weingast B.R. Self-enforcing federalism. Journal of Law, Economics, and Organization, 2005. 21(1), 127.

7. De Figueiredo R.J.P., McFaul M., \& Weingast B.R. Constructing selfenforcing federalism in the early United States and modern Russia. Publius, 2007. 37(2), 160-189.

8. Filippov M., Ordeshook P.C., \& Shvetsova O. Designing federalism: A theory of self-sustainable federal institutions. Cambridge, UK: Cambridge University Press. 2004. - P. 136.

9. Gorenburg D. Minority ethnic mobilisation in the Russian Federation. Cambridge, UK: Cambridge University Press. 2003. - P. 126.

10. Greif A., \& Laitin D.D. A theory of endogenous institutional change. American Political Science Review, 2004. 98, 633.

11. Hechter M. Containing nationalism. Oxford, UK: Oxford University Press. 2000. - P.116.

12. Heinemann-Gruder A. Der heterogene Staat. Foderalismus und regionale Vielfalt in Rufiland [The heterogeneous state. Federalism and regional diversity in Russia]. Berlin: Arno Spitz. 2000. - P. 131.

13. Keating M. So many nations, so few states: Territory and nationalism in the global era. In A. G. Gagnon \& J. Tully (Eds.), Multinational democracies. Cambridge, UK: Cambridge University Press. 2001. - pp. 43-62.
14. Kymlicka W. Is federalism a viable alternative to secession? In P. Lehning (Ed.), Theories of secession (p. 133). London: Routledge. 1998

15. McGarry J. Federal political systems and national minorities. In A. L. Griffiths (Ed.), Handbook of federal countries 2002 (P. 434). Montreal: McGill-Queen's University Press.

16. Obydenkova A. Institutional tools of conflict management - asymmetrical federalism in ethnic-territorial conflicts: Quantitative analysis of Russian regions. Peace, Conflict and Development, 2005. 7, 266.

17. Requejo F. Federalism and national groups. International Social Science Journal, 2001. 53 (167). - P. 45.

18. Solnick S. Will Russia survive? Center and periphery in the Russian Federation. In B.R. Rubin \& J. Snyder (Eds.), Post-Soviet political order: Conflict and state building (P. 59). London: Routledge. 1998.

19. Stepan A. Arguing comparative politics. Oxford, UK: Oxford University Press. 2001. 26(2). - pp. 327-328.

20. Tarlton C.D. Symmetry and asymmetry as elements of federalism: A theoretical speculation. Journal of Politics, 1965. 27(4), 871.

21. Tishkov V. Ethnicity, nationalism and conflict in and after the Soviet Union: The mind aflame. Thousand Oaks, CA: SAGE. 1997. - P. 56.

22. Treisman D.S. Russia's «ethnic revival”: The separatist activism of regional leaders in a postcommunist order. World Politics, 1997. 49, 226-228.

23. Tsebelis G. Nested games: Rational choice in comparative politics. Berkeley: University of California Press. 1990. - P. 245

24. Watts R.L. Comparing federal systems $\left(2^{\text {nd }} e d.\right)$. Montreal: McGill-Queen's University Press. 1999. P. 67.

25. Watts R.L. The theoretical and practical implications of asymmetrical federalism. In R. Agranoff (Ed.), Accommodating diversity: Asymmetry in federal states (pp. 24-42). Baden-Baden, Germany: Nomos. 1999. - P. 37.

\section{References (transliteration):}

1. Medvedev N.P. Rol' deklaratsii o gosudarstvennom suverenitete RSFSR i federativnogo dogovora v protsesse transformatsii territorial'no-politicheskogo ustroistva sovremennoi Rossii./ Pod red. R.G. Abdulatipova (Voprosy natsional'nykh i federativnykh otnoshenii). - M.: RAGS, 2003. - S. 23. 
DOI: $10.7256 / 1811-9018.2014 .1 .10711$

При цитировании этой статьи сноска на dоі обязательна

\section{Право и политика 1 (169) • 2014}

2. Umnova I.A. Konstitutsionnye osnovy sovremennogo rossiiskogo federalizma. - M.: DELO, 1998. - S. 53.

3. Agranoff R. Intergovernmental relations and the management of asymmetry in federal Spain. In R. Agranoff (Ed.), Accommodating diversity: Asymmetry in federal states (p. 97). Baden-Baden, Germany: Nomos.1999.

4. Burgess M., \& Gress F. Symmetry and asymmetry revisited. In R. Agranoff(Ed.), Accommodating diversity: Asymmetry in federal states (p. 53). Baden-Baden, Germany: Nomos. 1999.

5. Congleton R.D., Kyriacou A., \& Bacaria, J. A theory of menu federalism: Decentralization by political agreement. Constitutional Political Economy, 2003. 14, 170.

6. De Figueiredo R.J.P., \& Weingast B.R. Self-enforcing federalism. Journal of Law, Economics, and Organization, 2005. 21(1), 127.

7. De Figueiredo R.J.P., McFaul M., \& Weingast B.R. Constructing selfenforcing federalism in the early United States and modern Russia. Publius, 2007. 37(2), 160-189.

8. Filippov M., Ordeshook P.C., \& Shvetsova O. Designing federalism: A theory of self-sustainable federal institutions. Cambridge, UK: Cambridge University Press. 2004. - P. 136.

9. Gorenburg D. Minority ethnic mobilisation in the Russian Federation. Cambridge, UK: Cambridge University Press. 2003. - P. 126.

10. Greif A., \& Laitin D.D. A theory of endogenous institutional change. American Political Science Review, 2004. 98, 633.

11. Hechter M. Containing nationalism. Oxford, UK: Oxford University Press. 2000. - P.116.

12. Heinemann-Gruder A. Der heterogene Staat. Foderalismus und regionale Vielfalt in Rufiland [The heterogeneous state. Federalism and regional diversity in Russia]. Berlin: Arno Spitz. 2000. - P. 131.

13. Keating M. So many nations, so few states: Territory and nationalism in the global era. In A. G. Gagnon \& J. Tully (Eds.), Multinational democracies. Cambridge, UK: Cambridge University Press. 2001. - pp. 43-62.
14. Kymlicka W. Is federalism a viable alternative to secession? In P. Lehning (Ed.), Theories of secession ( $p$. 133). London: Routledge. 1998.

15. McGarry J. Federal political systems and national minorities. In A. L. Griffiths (Ed.), Handbook of federal countries 2002 (P. 434). Montreal: McGill-Queen's University Press.

16. Obydenkova A. Institutional tools of conflict management - asymmetrical federalism in ethnic-territorial conflicts: Quantitative analysis of Russian regions. Peace, Conflict and Development, 2005. 7, 266.

17. Requejo F. Federalism and national groups. International Social Science Journal, 2001. 53 (167). - P. 45.

18. Solnick S. Will Russia survive? Center and periphery in the Russian Federation. In B.R. Rubin \& J. Snyder (Eds.), Post-Soviet political order: Conflict and state building (P. 59). London: Routledge. 1998.

19. Stepan A. Arguing comparative politics. Oxford, UK: Oxford University Press. 2001. 26(2). - pp. 327-328.

20. Tarlton C.D. Symmetry and asymmetry as elements of federalism: A theoretical speculation. Journal of Politics, 1965. 27(4), 871.

21. Tishkov V. Ethnicity, nationalism and conflict in and after the Soviet Union: The mind aflame. Thousand Oaks, CA: SAGE. 1997. - P. 56.

22. Treisman D.S. Russia's «ethnic revival": The separatist activism of regional leaders in a postcommunist order. World Politics, 1997. 49, 226-228.

23. Tsebelis G. Nested games: Rational choice in comparative politics. Berkeley: University of California Press. 1990. - P. 245.

24. Watts R.L. Comparing federal systems (2nd ed.). Montreal: McGill-Queen's University Press. 1999. P. 67.

25. Watts R.L. The theoretical and practical implications of asymmetrical federalism. In R. Agranoff (Ed.), Accommodating diversity: Asymmetry in federal states (pp. 24-42). Baden-Baden, Germany: Nomos. 1999. - P. 37. 